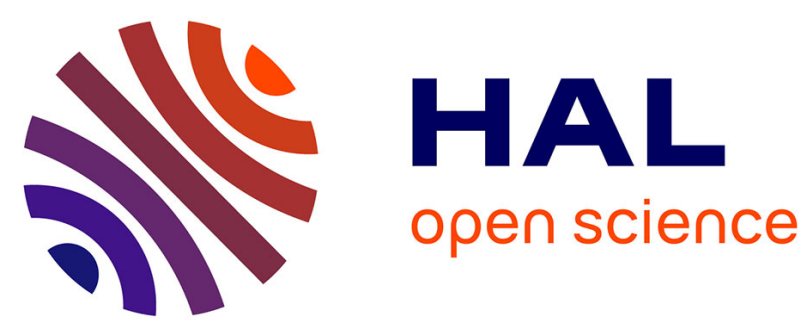

\title{
Evidence for a new human CYP1A1 regulation pathway involving PPAR- $\alpha$ and 2 PPRE sites
}

E. Seree, Pierre-Henri Villard, M Pascussi, T Pineau, P. Maurel, Q. B.

Nguyen, F. Fallone, P.-M. Martin, S. Champion, B. Lacarelle, et al.

\section{- To cite this version:}

E. Seree, Pierre-Henri Villard, M Pascussi, T Pineau, P. Maurel, et al.. Evidence for a new human CYP1A1 regulation pathway involving PPAR- $\alpha$ and 2 PPRE sites. Gastroenterology, 2004, 127 (5), pp.1436 - 1445. 10.1053/j.gastro.2004.08.023 . hal-01773769

\section{HAL Id: hal-01773769 \\ https://hal.science/hal-01773769}

Submitted on 11 May 2018

HAL is a multi-disciplinary open access archive for the deposit and dissemination of scientific research documents, whether they are published or not. The documents may come from teaching and research institutions in France or abroad, or from public or private research centers.
L'archive ouverte pluridisciplinaire HAL, est destinée au dépôt et à la diffusion de documents scientifiques de niveau recherche, publiés ou non, émanant des établissements d'enseignement et de recherche français ou étrangers, des laboratoires publics ou privés. 


\section{Evidence for a new human CYP1A1 regulation pathway involving PPAR $\alpha$ and two PPRE sites.}

Abbreviated title : PPAR $\alpha$ regulates CYP1A1 expression

Sérée $^{1 \uparrow \S}$ E., Villard ${ }^{1 \S}$ P-H., Pascussi ${ }^{2}$ J-M., Pineau ${ }^{3}$ T., Maure ${ }^{2}$ P., Nguyen ${ }^{1}$ Q. B., Fallone $^{1}$ F., Martin ${ }^{4}$, P-M., Champion ${ }^{1}$ S, Lacarelle ${ }^{1}$ B., Savouret ${ }^{5}$ J-F., and Barra ${ }^{1}$ Y.

1 FRE CNRS 2737, Faculté de Pharmacie, 27 Boulevard Jean Moulin, 13385, Marseille cedex 5, France; 2 INSERM U128, 1919 route de Mende, 34293 Montpellier cedex 5, France; 3 Laboratoire de Pharmacologie et Toxicologie, I.N.R.A., BP3, 31931 Toulouse, Cedex 9, France; 4 Laboratoire de Transfert d'Oncologie Biologique, Faculté de Médecine secteur Nord, Boulevard Dramard, 13916 Marseille cedex 20, France ; 5 UMR-S 530 INSERM - Université Paris 5, Centre Universitaire-UFR Biomédicale, 45, Rue des Saints-Pères, 75006 Paris, France.

• : Corresponding author: Eric Sérée, ISPDCT CNRS 2737, Faculté de Pharmacie,

27 Boulevard Jean Moulin, 13385, Marseille, cedex 5, France. Tel/Fax (33)4 9183 5594, Email: eric.seree@pharmacie.univ-mrs.fr

$\S:$ The two first authors participated equally to this work

Key words : CYP1A1, PPAR $\alpha$, PPAR $\gamma$, PPRE, AhR, cytochrome P450 


\section{Abstract}

Background § aims: Cytochrome P450 1A1 (CYP1A1) catalyzes the degradation of endobiotics (estradiol, fatty acids...) and the bioactivation of numerous environmental procarcinogens such as arylamines and polycyclic aromatic hydrocarbons that were found in food. Several peroxysome proliferators and arachidonic acid derivatives enhance CYP1A1 activity, but the mechanisms involved remain unknown. The aim of this work was to study the role of PPAR receptors in CYP1A1 gene induction.

Methods: The role of PPAR transcription factors in CYP1A1 induction was assessed by means of Enzymatic activities, QRT-PCR, gene reporter assays, mutagenesis and

\section{EMSA.}

Results: We demonstrate that PPAR $\alpha$ agonists (WY-14643, bezafibrate, clofibrate and phthalate) induce human CYP1A1 gene expression, while 2,4-thiazolidinedione, a specific PPAR $\gamma$ agonist, represses it. The induction of CYP1A1 transcripts by WY-14643 was associated with a marked increase of EROD activity (10-fold at 200 $\mu \mathrm{M})$. Transfection of PPAR $\alpha \mathrm{CDNA}$ enhanced CYP1A1 mRNA induction by WY-14643 although WY-14643 failed to activate XRE sequences. Two PPRE sites were located at the positions $-931 /-919$ and $-531 /-519$ of CYP1A1 promoter. Their inactivation by directed mutagenesis, suppressed the inductive effect of WY-14643 on CYP1A1 promoter activation. EMSA and chromatin immunoprecipitation assay experiments demonstrated that the two CYP1A1 PPRE sites bind the PPAR $\alpha / R X R \alpha$ heterodimer.

Conclusions: We describe here a new CYP1A1 induction pathway involving PPAR $\alpha$ and two PPRE sites indicating that PPAR $\alpha$ ligands, which are common environmental compounds, may be involved in carcinogenesis. 


\section{Introduction}

Cytochromes P450 (CYPs) are hemoproteins involved in the metabolism of some endogenous compounds (estradiol, fatty acids) and numerous xenobiotics. CYPs are the main enzymes involved in the bioactivation of environmental procarcinogens. CYP1A1 catalyzes the bioactivation of polycyclic aromatic hydrocarbons (PAHs) and arylamines. PAHs are ubiquitous compounds found in tobacco smoke, industrial workplace, and food. Arylamines are pyrolysis derivatives of proteins. PAHs and arylamines are mainly involved in the etiology of smokers' lung cancers and colorectal cancers, respectively $(1,2)$. Moreover, CYP1A1 overexpression was associated with predisposition to various human cancers (3).

CYP1A1 is constitutively expressed in human enterocytes at relatively low level. However, it should be borne in mind that its expression is highly enhanced after exposition to chemical inducers, modulating cellular susceptibility to procarcinogens.

CYP1A1 gene expression is mainly regulated by the Aryl hydrocarbon Receptor (AhR) which is activated by a variety of xenobiotic compounds including dioxins, PAHs (4-6), flavonoids, indole and benzimidazole derivatives (7-9). The AhR is present in cytoplasm as an inactive form associated with two hsp90 and another protein, named AIP, involved in the stability of the complex AhR-hsp90. The ligand binding on AhR induces the dissociation of this complex and activates the receptor. After its activation, AhR is able to translocate in the nucleus, where it dimerizes with its partner, the aryl hydrocarbon receptor nuclear translocator (Arnt). This new complex binds specifically to enhancer DNA sequences within the CYP1A1 promoter called XRE (Xenobiotic Responsive Element). 
In spite of the fact that AhR plays a central role in CYP1A1 gene regulation, the activation of this transcription factor cannot always explain the observed CYP1A1 induction. For instance, carbaryl which is not an AhR ligand was found to induce CYP1A1 (10) by a mechanism not yet characterized.

AhR excepted, the other transcription factor involved in CYP1A1 induction was RAR but the level of induction reached was relatively faint (11).

It has been previously demonstrated that induction of CYP1A1 activity can be obtained by cell culture agitation, with a level comparable to those obtained with exposure to $0.1 \mathrm{nM}$ TCDD (2,3,7,8-tetrachlorodibenzo-p-dioxine) (12). Increasing shear stress leads to an increase of arachidonic acid level $(13,14)$ and arachidonic acid metabolites are PPAR $\alpha$ ligands (15). Using arachidonic acid and different phospholipid metabolism inhibitors, Mufti et al. (12) demonstrated that arachidonic acid and derivatives induce CYP1A1 gene activity and that cell stress induces phospholipase $D$, resulting in the formation of phosphatidic acid which activates phospholipase A2, resulting in the release of arachidonic acid. The metabolism of arachidonic acid probably resulted in a metabolite that, by an as yet unknown mechanism, induced CYP1A1 (12).

Moreover, it was demonstrated that peroxisome proliferators, such as phthalates, can increase the DNA adducts induced by the bioactivation of benzo(a)pyrene which is mainly catalyzed by CYP1A1 (16). The mechanism involved in this increase of DNA adducts was not characterized. So, phthalates appeared to be inducers of CYP1A1 activity. To date, it has been demonstrated that some phthalate derivatives are potent agonist ligands of PPAR $\alpha$ and to a lesser extent of PPAR $\gamma(17)$. We hypothesized that the potentiation of benzo(a)pyrene DNA adducts by phthalates could be related to CYP1A1 induction via the PPAR pathway. 
The aim of this study was to evaluate the effect of PPAR $\alpha$ ligands such as WY-14643 (a specific PPAR $\square$ ligand), Bezafibrate (BZF), Clofibrate (CF), Mono(2ethylhexyl)phthalate (MEHP) or specific PPAR $\square$ ligand such as Thiazolidinedione (TZD) on CYP1A1 expression in CaCo-2 cells. We demonstrated that CYP1A1 is highly inducible by PPAR $\alpha$ ligands. This induction specifically involves the transcription factor PPAR $\alpha$ and requires 2 PPRE sites located within the CYP1A1 promoter (positions -931/-919 and -531/-519). Our data characterize a new PPAR $\alpha-$ mediated CYP1A1 regulation pathway. This may be the basis of carcinogenesis by many environmental compounds acting as PPAR $\alpha$ ligands. 


\section{Materials and Methods}

Chemicals WY-14643 were purchased from VWR (France), 2-4, thiazolidinedione, 3-methylcholanthrene (3-MC), clofibrate (CF), bezafibrate (BZF) and dimethylsulfoxide were purchased from SIGMA (France) and Mono(2ethylhexyl)phthalate (MEHP) from TCI Europe (Belgium).

Cell culture and treatments Human colic adenocarcinoma CaCo-2, the hepatoma HepG2, the adenocarcinoma A549 cells and the primoculture of human keratinocytes were used. As soon as the CaCo-2 cells reached confluence, the culture medium was changed and $24 \mathrm{~h}$ later, they were further treated during $6 \mathrm{~h}$ with either the PPAR $\alpha$ agonists such as WY-14643 (10, 30, 100, 200, and $400 \mu \mathrm{M}) .100 \mu \mathrm{M}$ MEHP, $50 \mu \mathrm{M}$ clofibrate, $50 \mu \mathrm{M}$ bezafibrate or the PPAR $\gamma$ agonist 2, 4-Thiazolidinedione $(200 \mu \mathrm{M})$ or the AhR ligand 3-MC $(1 \mu \mathrm{M})$. In the same conditions, HepG2, keratinocytes and A549 were treated with $200 \mu \mathrm{M}$ of WY-14643 and $1 \mu \mathrm{M} 3-\mathrm{MC}$. 3MC was used as control CYP1A1 inducer.

QRT-PCR experiments Total RNA was isolated from cells using Nucleospin RNAll (Macherey Nagel, France). One $\mu \mathrm{g}$ of total RNA was reverse-transcribed in $30 \mu \mathrm{l}$ using GibcoBRL M-MLV reverse-transcriptase (Life Technologies, Cergy Pontoise, France) in its own buffer and random primers at $37^{\circ} \mathrm{C}$ for $1 \mathrm{~h} . \mathrm{CYP} 1 \mathrm{~A} 1$ mRNA expression normalized to $\beta 2$-microglobulin expression was determined using the LightCycler System (RocheDiagnostic, France) and the Faststart DNA master SYBRGreen I Kit (Roche diagnostics). The primers for CYP1A1 and $\beta 2$-microglobulin were as follow: 


\section{CYP1A1-S: 5'AAGAGGAGCTAGACACAGT3'}

CYP1A1-AS: 5'GAAACCGTTCAGGTAGGA3'

B2m-S: 5'CCGACATTGAAGTTGACTTAC3'

B2m-AS: 5'ATCTTCAAACCTCCATGATG3'

PCR was performed with $5 \mathrm{mM} \mathrm{MgCl}_{2}, 0.25 \mu \mathrm{M}$ of each primer and LightCycler FastStart DNA Master SYBR Green I mix in a total volume of $16 \mu \mathrm{l}$. Cycling conditions were as follows: 10 min denaturation at $95^{\circ} \mathrm{C}$, followed by 45 cycles of $10 \mathrm{~s}$ denaturation at $95^{\circ} \mathrm{C}, 8 \mathrm{~s}$ primer annealing at $55^{\circ} \mathrm{C}$ and $8 \mathrm{~s}$ of fragment elongation at $72^{\circ} \mathrm{C}$. The melting curve was analyzed with the LightCycler software and quantitation was done with RelQuant software (Roche Diagnostic, France).

Three independent experiments were at least realized in triplicate.

EROD activity CaCo-2 cells were either untreated or treated with different concentrations of WY-14643 $(10,30,100$ and $200 \mu \mathrm{M})$. Ethoxyresorufin O-Deethylase (EROD) activity, mainly supported by CYP1A1, was determined according to the method of Burke et al. (18), slightly modified by Kennedy et al. (19). The fluorescence of resorufin produced during the reaction was measured using a CYTOFLUOR Multi-well plate reader series 400 (PerSeptive Biosystems) with 530 $\mathrm{nm}$ excitation and $590 \mathrm{~nm}$ emission wavelengths. Fluorescence values were converted to picomoles using a calibration curve of resorufin fluorescence and EROD activity was expressed as pmol of resorufin/min/mg total cellular protein.

Cloning of CYP1A1 XRE sequences Sense and antisense oligonucleotides containing two CYP1A1 XRE sites were synthesized with addition of Hind III and Xba I restriction sites at the 5' and 3' ends respectively. After hybridization and their 
digestion by Hind III and Xba I, these two oligonucleotides were cloned in the corresponding sites of the PBLCAT2 vector containing a thymidine kinase promoter (TK). This construction was named XRE-TK-CAT. The oligonucleotide sense used is :

5'CCGCCCAAGCTTCCTCCCCCCTCGCGTGACTGCGAGGGGAAGGAGGCGTGG CCACACGTCTAGACTAGCT3'. The XRE sites are in bold letters and the Hind III and $X b a I$ restriction sites are in italic characters and underlined.

CAT assays The chimeric construction pRNH25c containing the $-1140 /+80$ region of CYP1A1 gene driving chloramphenicol acetyltransferase (CAT) gene expression was used. Cells in 6 well-plates were transiently transfected with $1 \mu \mathrm{g}$ of pRNH25c using lipofectin (Life Technologies, France). The transfection was performed as specified by the supplier. $24 \mathrm{~h}$ after the end of the transfection, cells were treated during $48 \mathrm{~h}$ with $200 \mu \mathrm{M}$ WY-14643 or $1 \mu \mathrm{M}$ 3-MC. CAT expression was then evaluated by the amount of CAT protein using the CAT Elisa System (Roche Diagnostic, France).

A similar experiment was realized with a construct coding PPAR $\alpha$. Transfected cells with $1 \mu \mathrm{g}$ of cDNA or untransfected cells were then either untreated or treated with $200 \mu \mathrm{M}$ WY-14643 during $48 \mathrm{~h}$. CYP1A1 mRNA level was determined as described above.

Three independent experiments were at least realized in triplicate.

Site-Directed mutagenesis of the CYP1A1 promoter The PPRE mutations of pRNH25c were introduced using the QuickChange site-directed mutagenesis kit (Stratagene, France) to obtain the $\mathrm{pRNH} 25 \mathrm{c}(\triangle \mathrm{PPRE} 1)$, the $\mathrm{pRNH} 25 \mathrm{c}(\triangle \mathrm{PPRE} 2)$ and the $\mathrm{pRNH} 25 \mathrm{c}(\triangle \mathrm{PPRE} 1+2)$. The primers sense and antisense were used for 
mutagenesis. The primers sens were as follows (the PPRE core was underlined and bold letters represent mutated nucleotides compared to the wild type sequence $(\mathrm{Wt})$ ): Wt 1: 5'GGACGGGCCGCCTGACCTCTGCCCCCTAGAGGGATGTCG3' PPRE1 muts : 5'GGACGGGCCGCCTGACCTCGATCCCCTAGAGGGATGTCG3' Wt 2: 5' GGCCTTCCGGCCCCGTGACCTCAGGGCTGGGGTCGCAGC 3' PPRE2 mut-s : 5'GGCCTTCCGGCCCCGTGAATTCAGGGCTGGGGTCGCAGC3' Presence of the mutations was verified by DNA sequencing. Cells were transfected by either the pRNH25c or pRNH25c( $\triangle \mathrm{PPRE} 1)$ or pRNH25c( $\triangle \mathrm{PPRE} 2)$ or pRNH25c $(\triangle P P R E 1+2)$ and after a 48 h-treatment with WY-14643 $(200 \mu \mathrm{M})$ the CAT expression was evaluated as described above.

In vitro translation and electromobility shift assays Electromobility shift assays were performed using PPAR $\alpha$ and $\mathrm{RXR} \alpha$ prepared by in vitro translation using a coupled transcription-translation system (Promega, France). Proteins were incubated for 20 minutes at room temperature with $50.000 \mathrm{cpm}$ of T4 polynucleotide kinaselabeled oligonuclotides in $10 \mathrm{mM}$ Tris (pH8.0), $100 \mathrm{mM} \mathrm{KCl}, 10 \%$ glycerol, $1 \mathrm{mM}$ dithiothreitol, $1 \mu \mathrm{g}$ poly $(\mathrm{dldC})$ and $0.5 \mu \mathrm{g}$ of salmon sperm. The mixture was then submitted to electrophoresis on a $4 \%$ polyacrylamide gel in $45 \mathrm{mM}$ Tris Base, $45 \mathrm{mM}$ boric acid, $1 \mathrm{mM}$ EDTA. The following oligonucleotides were used either as radiolabeled probes or as competitors (the sense strand is shown, with core sequence underlined and mutation in bold face): PPRE Cons, 5'CCGCCAAGCTTGCTCCGCCAGGTCACAGGTCACTAG ; CYP1A1-PPRE1， 5'GGACGGGCCGCCTGACCTCTGCCCCCTAGAGGGATGTCG; CYP1A1-PPRE2, 5'GGCCTTCCGGCCCCGIGACCTCAGGGCTGGGGTCGCAGC; CYP1A1-PPRE1 mutant, 5'-GGACGGGCCGCCTGACCTCGATCCCCTAGAGGGATGTCG; CYP1A1- 
PPRE2 mutant, 5'-GGCCTTCCGGCCCCGTGAATTCAGGGCTGGGGTCGCAGC . Anti-PPAR $\alpha$ antibody (Santa Cruz Biotechnology) was used for the "supershift" assays. Autoradiography was carried out by exposing the dried gel to Kodac X-AR film.

Chromatin ImmunoPrecipitation assay (ChIP) Confluent CaCo-2 cells $(4 \times 100 \mathrm{~mm}$ dish) were treated with or without WY-14643 $200 \mu \mathrm{M}$ for 1 hour. Cells were then fixed with formaldehyde at $37^{\circ} \mathrm{C}$ for $15 \mathrm{~min}$. The reaction was then stopped by addition of $1 \mathrm{ml} 1 \mathrm{M}$ glycine and incubation for $15 \mathrm{~min}$ at room temperature. Cells were harvested, and pooled. Soluble chromatin prepared with a chromatin immunoprecipitation assay kit (Upstate Biotechnology Inc) was precleared for $1 \mathrm{~h}$ with salmon sperm DNA-BSA/Protein A-Sepharose. Precleared chromatin was then incubated for $16 \mathrm{~h}$ with $10 \mu \mathrm{g}$ of anti-human PPAR $\alpha$ antibodies ( $\mathrm{N}-19$ from Santa Cruz Biotechnology, or MIA-822 from Affinity BioReagents) or $10 \mu \mathrm{g}$ of control mice IgG antibody (Sigma). Immune complexes were collected with $50 \mu \mathrm{l}$ of Protein G-Sepharose (Santa Cruz Biotechnology) supplemented with salmon sperm DNA (200 $\mu \mathrm{g} / \mathrm{ml})$ and BSA $(1 \mathrm{mg} / \mathrm{ml})$ and purified according to manufacturer's recommendations (Upstate Biotechnology Inc). Purified DNA samples (phenolchlorophorm-isoamyl alcohol and further on Qiagen columns) were used as template for PCR performed for 40 cycles (Pfx Taq DNA polymerase, Invitrogen). Similarly purified DNA fragments from the chromatin extracts (input) were used as control (PCR performed for 30 cycles). Cycling conditions were as follows: $3 \mathrm{~min}$ denaturation at $93^{\circ} \mathrm{C}$, followed by 30 or 40 cycles of $30 \mathrm{~s}$ denaturation at $91^{\circ} \mathrm{C}, 30 \mathrm{~s}$ primer annealing at $55^{\circ} \mathrm{C}$ and $1 \mathrm{~min}$ of elongation at $72^{\circ} \mathrm{C}$. Primers used for proximal CYP1A1 PPREs containing promoter region amplification were 
5'-GCCTCCGGTCCTTCACAC-3' and 5'-CGCTACAGCCTACCAGGACT-3' (-1000 to -413 upstream of the transcriptional start site), while primers used for distal CYP1A1 promoter region (harboring no PPRE sites) were 5'-CACAACTTGCACTGCCCTTA-3' and 5'-CCAACAGCTCATTGAGAACG-3' (-4053 to -3780 upstream of the transcriptional start site).

Statistical analysis Statistical analysis were performed using the Newman-Keuls test. Data were considered statistically significant at a $p<0.05$. Significant results were noted with * or $^{* \star}$ or ${ }^{* \star \star}$ for a $p<0.05, p<0.01$ and $p<0.001$ respectively.

\section{Results}

\section{Induction of CYP1A1 gene by PPAR ligands}

CaCo-2 cells were treated during $6 \mathrm{~h}$ with increasing concentrations of WY-14643 (10-400 $\mu \mathrm{M})$, or $50 \mu \mathrm{M}$ BZF, or $50 \mu \mathrm{M}$ CF, or $100 \mu \mathrm{M}$ MEHP, or $200 \mu \mathrm{M}$ TZD or $1 \mu \mathrm{M}$ 3-MC. CYP1A1 mRNA was then evaluated by quantitative real-time (QRT-PCR) analysis. The results presented in Fig.1A show that TZD does not increase and even decreased CYP1A1 gene expression. In contrast, CYP1A1 mRNA levels increased after treatments with the PPAR $\alpha$ ligands such as WY-14643 or BZF or CF or MEHP. The WY-14643 CYP1A1-mediated induction was dose dependent and reached the plateau at $200 \mu \mathrm{M}(6$-fold).

The results presented in Figure 1B also show that CYP1A1 expression was induced after $200 \mu \mathrm{M}$ WY-14643 treatment of various human cell lines other than CaCo-2 including HepG2 (hepatoma), in a primary culture of human keratinocytes 
and A549 (lung adenocarcinoma). However, the CYP1A1 inductions obtained in these cells were lower than in CaCo-2.

\section{Induction of CYP1A1 EROD activity by WY-14643}

The EROD activity was analyzed after treatment of CaCo-2 cells with increasing concentrations of WY-14643 (10-200 $\mu \mathrm{M})$. The results, shown in Fig. 2, indicate that the CYP1A1 EROD activity was dose dependently induced by WY-14643 (10-fold at $200 \mu \mathrm{M})$ and that the induction obtained with $200 \mu \mathrm{M}$ WY-14643 was similar to those obtained with $1 \mu \mathrm{M}$ 3-MC (12.6-fold).

\section{WY-14643 did not stimulate the XRE sequence}

By means of CAT assay analysis, we investigated whether WY-14643, a potent PPAR $\alpha$ ligand, was able to stimulate the XRE target sequences of AhR. Cells were treated either with $1 \mu \mathrm{M}$ 3-MC, or $200 \mu \mathrm{M}$ WY-14643 after transient transfection with a XRE-TKCAT construct. Figure $3 \mathrm{~A}$ shows that $3-\mathrm{MC}$, a classic AhR ligand, activated CAT expression 2.1-fold, while WY-14643 did not increase CYP1A1 gene expression via the AhR signaling pathway.

Transfection with PPAR $\alpha$ cDNA increases the CYP1A1 induction by WY-14643

To strengthen the implication of PPAR $\alpha$ in CYP1A1 induction by WY-14643, PPAR $\alpha$ transfected CaCo-2 cells were treated with WY-14643. Fig. 3 B shows that PPAR $\alpha$ transfection doubled d CYP1A1 mRNA induction by $200 \mu \mathrm{M}$ WY-14643 (10fold) as compared to cells receiving the reporter gene alone (6-fold). 


\section{Two PPRE sequences located within the CYP1A1 gene promoter are}

involved in the CYP1A1 induction by WY-14613

CYP1A1 promoter gene analysis, using Mathinspector (20), revealed that two putative PPRE sites are located within the promoter at positions -931/-919 (CYP1A1PPRE1) and -531/-519 (CYP1A1PPRE2) respectively.

To confirm that PPAR $\alpha$ ligands were able to induce CYP1A1 mRNA by activation of its promoter, we transfected CaCo-2 cells with either the pRNH25c construct containing the wild type CYP1A1 promoter or with the pRNH25c construct

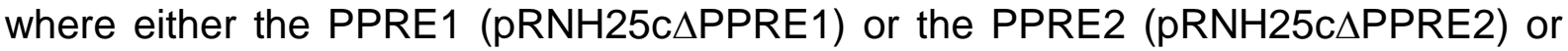
the PPRE1+2 (pRNH25c $\triangle \mathrm{PPRE} 1+2)$ sequences were mutated. Cells were then treated with either $200 \mu \mathrm{M}$ WY-14643, or $1 \mu \mathrm{M}$ 3-MC for $48 \mathrm{~h}$. Figure 4 shows that WY-14643 and 3-MC efficiently induced the transactivation of the CYP1A1 wild type promoter pRNH25c (2.4-fold with $200 \mu \mathrm{M}$ WY-14643 and 4.6-fold with $1 \mu \mathrm{M}$ 3-MC). The mutation of one of the two CYP1A1 PPRE sites led to a decrease of CYP1A1 promoter activation by WY-14643. Indeed, the induction of CAT expression was lower using the pRNH25c $\triangle \mathrm{PPRE} 1$ or pRNH25c $\triangle \mathrm{PPRE} 2$ constructs (1.6-fold and 1.4fold respectively) as compared to the pRNH25c construct (2.4-fold). When the two sites were mutated $(p R N H 25 c \Delta P P R E 1+2)$ the decrease of WY-14643 effect was higher (1.1-fold at $200 \mu \mathrm{M}$ WY-14643).

\section{The two CYP1A1 PPRE sites were able to bind PPAR $\alpha$}

We first checked the binding of an in vitro translated PPAR $\alpha-R X R$ heterodimer to the two CYP1A1 putative PPRE sequences by gel shift assay (Fig. 5). As expected, a specific retarded band was observed when PPAR $\alpha$ and its partner RXR were incubated together with the target oligonucleotide (lane 5 and 11), but not when 
these receptors were incubated separately (lanes 3,4 and 9,10 ). We confirmed that the shift obtained using the CYP1A1 PPRE1 and PPRE2 was the consequence of the binding of PPAR $\alpha$ using a specific PPAR $\alpha$ antibody which produced a super shift shown in lanes 6 and 12 .

In addition, the specific PPAR $\alpha / R X R \alpha-P P R E$ complex was repressed in a dose-dependant manner when incubated in the presence of 10-fold (Fig. 6 lanes 7, 9, 11) or 50-fold (lanes $6,8,10$ ) excess of unlabeled consensus PPRE or unlabelled CYP1A1-PPRE1 or CYP1A1-PPRE2 sequences.

In the same conditions, a 50-fold excess of mutated PPRE1 or PPRE2 CYP1A1 sequences did not affect the binding of PPAR $\alpha / R X R \alpha$ on the PPRE consensus core (Fig 6 lanes 12 and 13 respectively). A supershifted band appeared using a PPAR $\alpha$ antibody (lane 14).

These observations showed that the in vitro translated heterodimer PPAR $\alpha / R X R \alpha$ binds to the two PPRE1 and PPRE2 sites within the CYP1A1 gene promoter.

To strengthen our demonstration, ChIP analysis was performed using $\mathrm{CaCo}-2$ cells untreated or treated with $200 \mu \mathrm{M}$ WY-14643 for $1 \mathrm{~h}$. We showed (Figure 7) that the PPAR $\alpha / R X R \alpha$ heterodimer binds to the PPRE sites located within the proximal CYP1A1 gene promoter. 


\section{Discussion}

We characterized a new CYP1A1 regulation pathway involving the binding of PPAR $\alpha$ transcription factor on two PPRE sequences located within the 5' untranslated region of CYP1A1 gene.

The effects of agonists of PPAR $\alpha$ (WY-14643, CF, BZF and MEHP) and PPARy (TZD) on CYP1A1 mRNA expression levels were evaluated in Caco-2 cell line by real time QRT-PCR analysis. WY-14643 induced CYP1A1 mRNA in a dose dependent manner, up to 6 -fold as soon as $200 \mu \mathrm{M}$. Similarly, CYP1A1 mRNA level was increased after 6h treatment with other PPAR $\alpha$ ligands (CF, BZF, MEHP). The induction factors were lower than those observed with WY-14643, which is one of the most potent agonists of PPAR $\alpha$. These results confirmed that CYP1A1 is induced by different classes of PPAR $\alpha$ ligands including the fibrates and phthalates. In contrast, TZD led to a marked decrease of CYP1A1 transcript. Such an antagonist regulatory effect of these two transcription factors (PPAR $\alpha$ and PPAR $\gamma$ ) has already been described for some genes, such as VCAM-1 $(21,22)$. However, the repressive effect of PPAR $\gamma$ on CYP1A1 expression remains to be clarified and is presently under investigation in our laboratory. Moreover, transfection of PPAR $\alpha$ cDNA leads to a higher induction with WY-14643, strengthening the involvement in Caco-2 cell line of PPAR $\alpha$ in CYP1A1 regulation.

The CYP1A1 induction by PPAR $\alpha$ was not restricted to CaCo-2 cells as similar results were obtained with HepG2 hepatoma cells, A549 lung adenocarcinoma cells, and primary cultures of human keratinocytes. The effect of PPAR $\alpha$ ligands on CYP1A1 induction appears to be a general phenomenon and not restricted to colon cell lines. 
The induction of CYP1A1 mRNA by WY-14643 was associated with an increase of EROD activity. This induction of EROD activity was similar to that obtained with $1 \mu \mathrm{M}$ 3-MC. Therefore, PPAR $\alpha$ agonists may increase the genotoxic effect of procarcinogens bioactivated by CYP1A1, such as PAH or arylamines. Such a phenomenon was previously described with two peroxisome proliferators, silvex and di(2-ethylhexyl)phthalate, which enhance BAP-induced DNA adducts (16).

To date, PPAR $\alpha$ ligands belonging to the fibrates class have been widely used as hypolipidemic drugs, and have never been implicated in human carcinogenesis, although they are well known hepatocarcinogens in rodents. The lack of such a side effect in humans may be related to the poor expression of PPAR $\alpha$ in liver. Our data suggest that expositions to environmental PPAR $\alpha$ ligands, including fibrate and chemical compounds such as phthalates or chlorophenoxyacetic pesticides, may increase CYP1A1 extrahepatic expression. Therefore, cells harboring a higher CYP1A1 expression would have a greater susceptibility to the genotoxic effect of CYP1A1 bioactivated procancerogens.

Since CYP1A1 is mainly regulated by the Ah receptor, it was logical to assume that WY-14643 could have a direct or indirect action on this transcription factor. However, using XRE-TK-CAT construct we showed that WY-14643 failed to activate XRE site, demonstrating that CYP1A1 induction by PPAR $\alpha$ ligand did not involve AhR.

Sequence analysis of CYP1A1 promoter revealed the presence of two putative PPRE sites. Indeed, treatment with WY-14643 increased CAT expression when cells were transiently transfected with $\mathrm{pRNH} 25 \mathrm{c}$ harboring the wild-type CYP1A1 promoter. The results obtained in Fig. 4 clearly demonstrate that the mutation of one PPRE site ( $\triangle \mathrm{PPRE} 1$ or $\triangle \mathrm{PPRE} 2)$ reduces the CAT induction while no induction 
occurred with pRNH25c ( $\triangle \mathrm{PPRE} 1+2)$. So, it appears that the two PPRE sites located within the promoter at positions -931/-919 (CYP1A1 PPRE1) and -531/-519 (CYP1A1 PPRE2) respectively were necessary for the CYP1A1 induction by PPAR $\alpha$ ligands.

The direct role played by these 2 PPRE sites in the binding of PPAR transcription factor was evaluated first by EMSA. We found that even if the two sites diverge from the canonical DR1 sequence they are still able to bind PPAR $\alpha$ with good efficiency . PPAR $\alpha$ binding is no longer possible when mutations are introduced in these CYP1A1 PPRE sites. In order to demonstrate the in vivo relevance of these PPRE sites, we performed ChIP assays. We immunoprecipitated the human CYP1A1 gene promoter using two different anti-human PPAR $\alpha$ antibodies, demonstrating that PPAR $\alpha / R X R \alpha$ heterodimer binds in vivo on the CYP1A1 PPRE sites. We actually showed that with or without WY-14643 treatment, PPAR $\alpha / R X R \alpha$ bound to the PPRE sites within the CYP1A1 promoter. This binding without any treatment has already been shown in $\mathrm{CaCo}-2$ for the carnitine palmitoyltransferase II gene (23). Recently, with a ChIP assay performed on mouse liver extract, IJpenberg et al (24) did not observe any PPAR $\alpha / R X R \alpha$ binding on PPRE site of malic enzyme gene in untreated mice but had to treat the animals with WY-14643 to visualize such a binding. Inversely, Jia et al (25) demonstrated in mouse liver extract, that PPAR $\alpha /$ $\mathrm{RXR} \alpha$ was already bound to PPRE site of L-PBE gene. Mouse treatment with WY-14643 seemed to increase this binding, but it is generally accepted that ChIP technology is qualitative but not quantitative.

To date, it has not been clearly documented whether, without any ligand the PPAR $\alpha / R X R \alpha$ heterodimer is unbound or bound to PPRE sites in an inactive conformation as has been largely described for RAR (26). It seems that the binding 
of PPAR $\alpha / R X R \alpha$ on PPRE sites in the presence or absence of PPAR $\alpha$ ligands is dependent on the nature of the tissue, the cell type and the gene studied.

The PPRE2 site appears to have an inverted orientation compared to a canonical consensus site while PPRE1 site displays a conventional orientation. Sequence alignment of CYP1A1 promoter (Figure 8) from various species demonstrates that PPRE1 and PPRE2 sites are highly conserved in human, rat and mouse species. Rat and mouse harbor the same PPRE1 and PPRE2 sequences and differ from humans in that they exhibit a unique base transition. Interestingly, the flanking regions are also conserved. Moreover, when sequence alignment was performed with CYP1A1 promoter from fish species, such as Anguilla japonica or Microgadus tomcod, we were unable to localize any PPRE sites, while several XRE sites are located within these promoters (data not shown). PPAR orthologs have already been described in fish species. Therefore the CYP1A1 regulation by PPAR $\alpha$ occurred tardily in the evolution of species, contrary to the regulation of CYP1A1 by AhR.

Until now, only the CYP4A, involved in fatty acid biotransformation, was known to be induced by PPAR $\alpha$ ligands within the CYPs superfamily, (27). Since CYP1A1, largely concerned in procarcinogens activation, is also implicated in fatty acid metabolism (28), it was logical to find its expression regulated through PPAR $\alpha$. Moreover, CYP1A1 modification level could have a physiological impact in terms of fatty acid metabolite levels.

Until now, CYP1A1 was known to be expressed and induced by the transcription factor AhR. This is the first time that another strong CYP1A1 induction pathway, apart from AhR, has been described. We demonstrated that CYP1A1 was highly induced by PPAR $\alpha$ via two PPRE sites within the promoter. The upregulation 
of CYP1A1 by PPAR $\alpha$ ligands may be involved in human carcinogenesis, notably in colon through an increase of CYP1A1-bioactivated procancerogens present in diet, such as arylamines. 
Acknowledgments: We thank R. Hines for the pRNH25c and Chacon Christine for her technical assistance. This study was partly funded by Ligue Nationale contre le Cancer, Comité du Rhône, Association de Recherche sur le Cancer (ARC) (research project no. 3410) and Institut National de la Santé et de la Recherche Médicale (INSERM) (Action Thématique Concertée Environnement et Santé, grant no. ASE 02048SSP), all these subsidies were granted to Dr. Sasco (IARC/INSERM). 


\section{References}

1. Guengerich FP. Metabolism of chemical carcinogens. Carcinogenesis $2000 ; 21: 345-351$

2. Ma JY, Yang HM, Barger MW, Siegel PD, Zhong BZ, Kriech AJ and Castranova V. Alteration of pulmonary cytochrome $p-450$ system: effects of asphalt fume condensate exposure. J Toxicol Environ Health 2002;65:1247-1260

3. Gonzalez FJ and Gelboin HV. Role of human cytochromes P450 in the metabolic activation of chemical carcinogens and toxins. Drug Metab Rev 1994;26:165-170

4. Li W, Harper P, Tang BK and Okey A. Regulation of cytochrome P450 enzymes by aryl hydrocarbon receptor in human cells: CYP1A2 expression in the LS180 colon carcinoma cell line after treatment with 2,3,7,8-tetrachlorodibenzo-pdioxin or 3-methylcholanthrene. Biochem Pharmacol 1998;56:599-612

5. Whithlock JP. Induction of cytochrome P4501A1. Annu Rev Pharmacol Toxicol 1999;39:103-125

6. Jones LC and Whitlock JP. Dioxin-inducible transactivation in a chromosomal setting. Analysis of the acidic domain of the Ah receptor. J Biol Chem $2001 ; 276: 25037-25040$

7. Quattrochi LC and Tukey RH. Nuclear uptake of the Ah dioxin receptor in response to omeprazole: transcriptional activation of the human CYP1A1 gene. Mol Pharmacol 1993;43:504-508 
8. Daujat $\mathrm{M}$, Charasse $\mathrm{S}$, Fabre I, Lesca $\mathrm{P}$, Joinaidi $\mathrm{Y}$, Larroque $\mathrm{C}$, Poellinger $\mathrm{L}$ and Maurel P. Induction of CYP1A1 gene by benzimidazole derivatives during Caco-2 cell differentiation. Evidence for an aryl-hydrocarbon receptor-mediated mechanism. Eur J Biochem 1996;237:642-652

9. Dzeletovic N, McGuire J, Daujat M, Tholander K, Ema M, Fujii-Kuriyama Y, Gbergman J, Maurel P and Pollinger L. Regulation of dioxin receptor function by omeprazole. J Biol Chem 1997;272:12705-12713

10. Ledirac N, Delescluse C, de Sousa G, Pralavorio M, Lesca P, Amichot M, Berge JB, Rahmani R. Carbaryl induces CYP1A1 gene expression in HepG2 and $\mathrm{HaCaT}$ cells but is not a ligand of the human hepatic Ah receptor. Toxicol Appl Pharmacol. 1997;144:177-82

11. Vecchini F, Lenoir-Viale MC, Cathelineau C, Magdalou J, Bernard BA and Shroot B. Presence of a retinoid responsive element in the promoter region of the human cytochrome P4501A1 gene. Biochem Biophys Res Commun $1994 ; 201: 1205-1212$

12. Mufti N. and Shuler M. Possible role of arachidonic acid in stress-induced cytochrome P450IA1 activity. Biotechnol. Prog. 1996;12:847-854

13. Nollert MU, Hall ER, Eskin SG, McIntire LV. The effect of shear stress on the uptake and metabolism of arachidonic acid by human endothelial cells. Biochem Biophys Acta. 1989;1005:72-80

14. Nollert MU, Eskin SG, McIntire LV. Shear stress increases inositol trisphosphate levels in human endothelial cells. Biochem Biophys Res Commun. 1990;170:281-7 
15. Hihi AK, Michalik L, Wahli W. PPARs: transcriptional effectors of fatty acids and their derivatives. Cell Mol Life Sci. 2002;59:790-8

16. Voskoboinik I, Ooi SG, Drew R, Ahokas JT. Peroxisome proliferators increase the formation of BPDE-DNA adducts in isolated rat hepatocytes. Toxicology. $1997 ; 122: 81-91$

17. Lovekamp-Swan, Jette A. and Davis B. Dual activation of PPARalpha and PPARgamma by mono-(2-ethylhexyl) phthalate in rat ovarian granulosa cells. Mol Cell Endocrinol. 2003;201:133-141

18. Burke MD, Thompson S, Elcombe CR, Halpert J, Haaparanta T and Mayer RT. Ethoxy-, pentoxy- and benzyloxyphenoxazones and homologues : a series of substrates to distinguish between different induced cytochromes P450. Biochem Pharmacol 1985;34:3337-3345

19. Kennedy SW, Jones SP and Bastien LJ. Efficient analysis of cytochrome P4501A catalytic activity, porphyrins, and total proteins in chicken embryo hepatocyte cultures with a fluorescence plate reader. Anal Biochem 1995;226:362-370

20. Quandt K, Frech K, Karas H, Wingender E and Werner T MatInd and MatInspector: New fast and versatile tools for detection of consensus matches in nucleotide sequence data. Nucleic Acids Res 1995;23:4878-4884.

21. Rival Y, Beneteau N, Taillandier T, Pezet M, Dupont-Passelaigue E, Patoiseau JF, Junquero D, Colpaert FC, Delhon A. PPARalpha and PPARdelta activators inhibit cytokine-induced nuclear translocation of NF-kappaB and expression of VCAM-1 in EAhy926 endothelial cells. Eur J Pharmacol. 2002;4352:143-51 
22. Marx N, Sukhova GK, Collins T, Libby P, Plutzky J. PPARalpha activators inhibit cytokine-induced vascular cell adhesion molecule-1 expression in human endothelial cells. Circulation 1999;99:3125-31

23. Barrero MJ, Camarero N, Marrero PF, and Haro D. Control of human carnitine palmitoyltransferase II gene transcription by peroxisome proliferator-activated receptor through a partially conserved peroxisome proliferator-responsive element. Biochem J 2003;369:721-9

24. IJpenberg A, Tan NS, Gelman L, Kersten S, Seydoux J, Xu J, Metzger D, Canaple L, Chambon P, Wahli W, and Desvergne B. In vivo activation of PPAR target genes by RXR homodimers. EMBO J 2004;23:2083-91

25. Jia Y, Qi C, Kashireddi P, Surapureddi S, Zhu YJ, Rao MS, Le Roith D, Chambon P, Gonzalez FJ, Reddy JK. Transcription coactivator PBP, the peroxisome proliferator-activated receptor (PPAR)-binding protein, is required for PPARalpha-regulated gene expression in liver. J Biol Chem 2004;279:24427-34

26. Bastien J, Rochette-Egly C. Nuclear retinoid receptors and the transcription of retinoid-target genes. Gene 2004;328:1-16

27. Aldridge TC, Tugwood JD and Green S. Identification and characterization of DNA elements implicated in the regulation of CYP4A1 transcription. Biochem $\mathrm{J}$ $1995 ; 306: 473-479$

28. Yamazaki H, Shimada T. Effects of arachidonic acid, prostaglandins, retinol, retinoic acid and cholecalciferol on xenobiotic oxidations catalysed by human cytochrome P450 enzymes. Xenobiotica 1999;29:231-41 

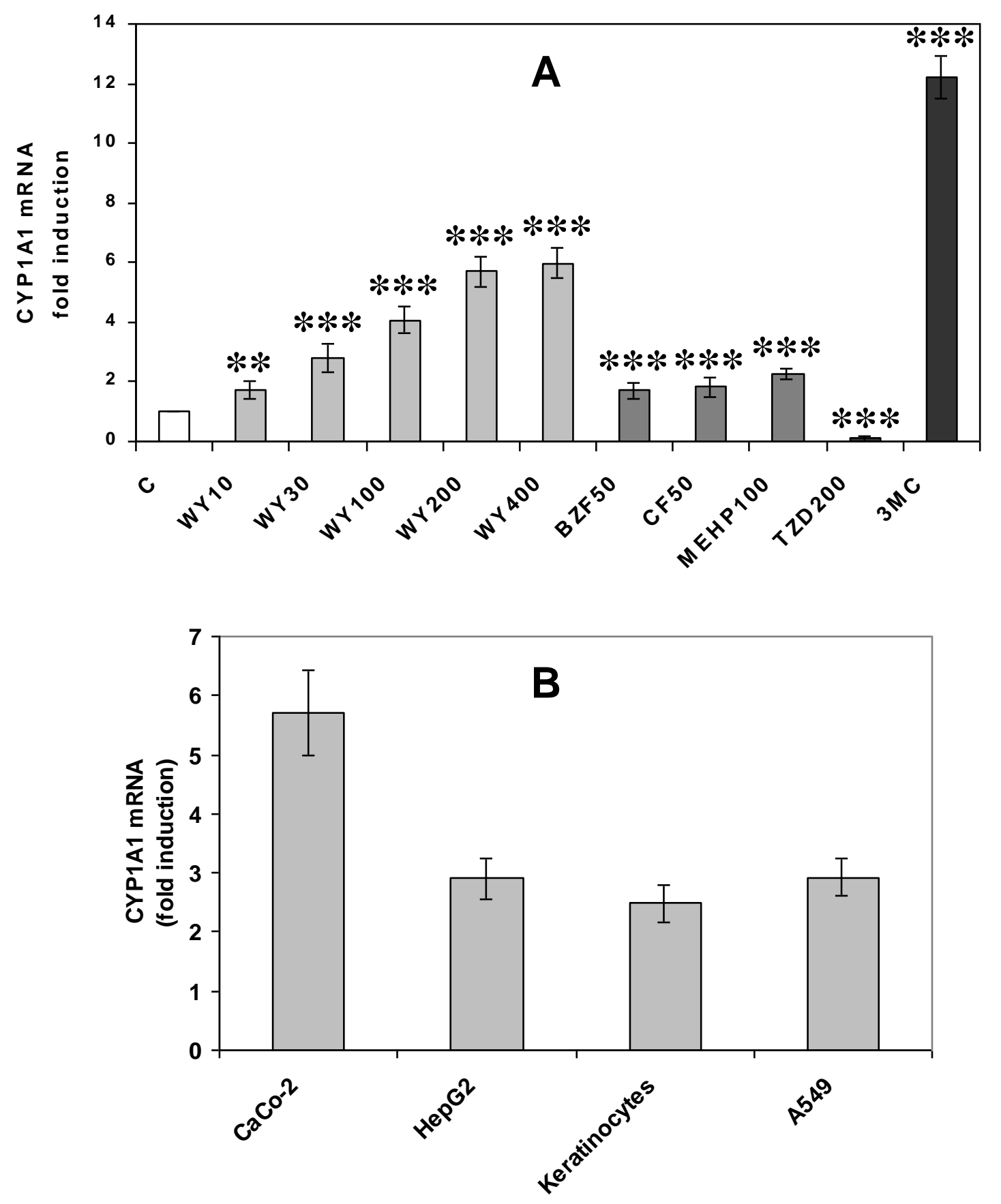

Figure 1 


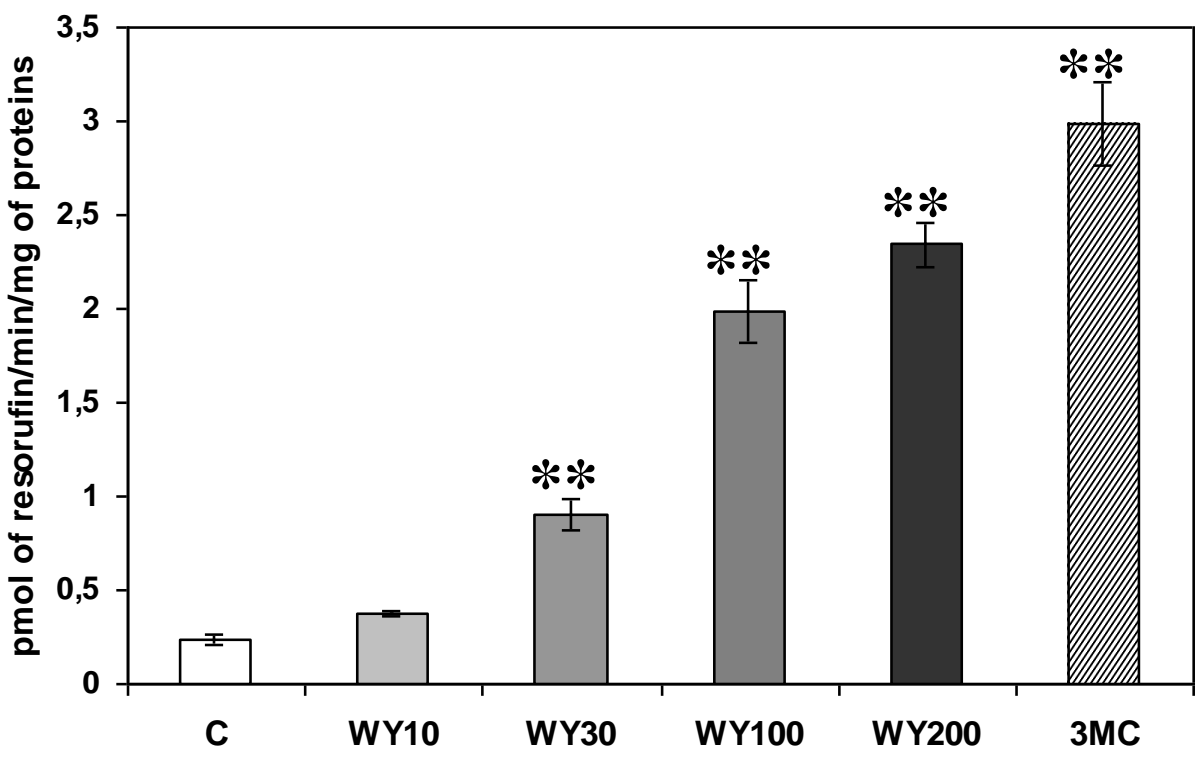

Figure 2 

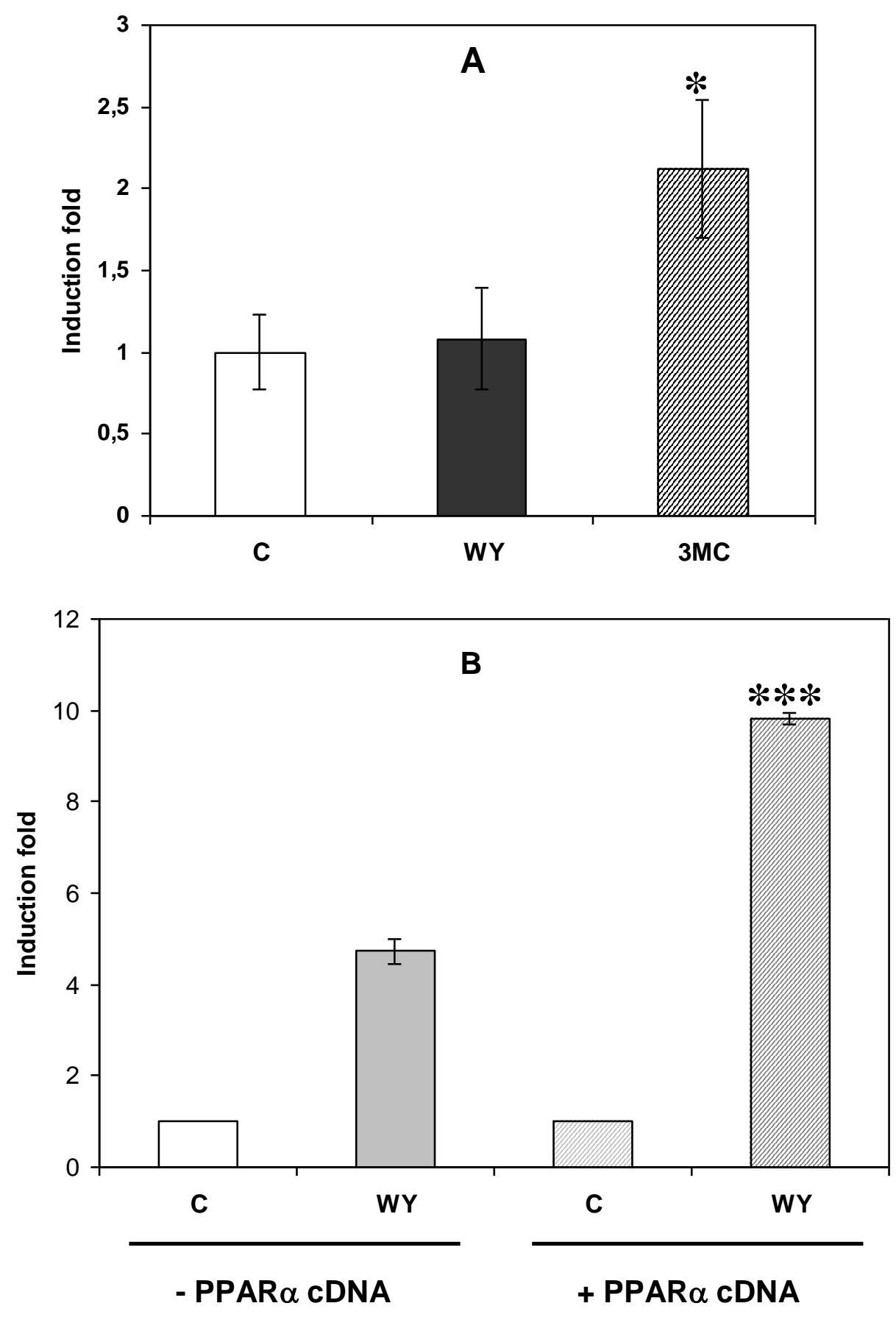

Figure 3 

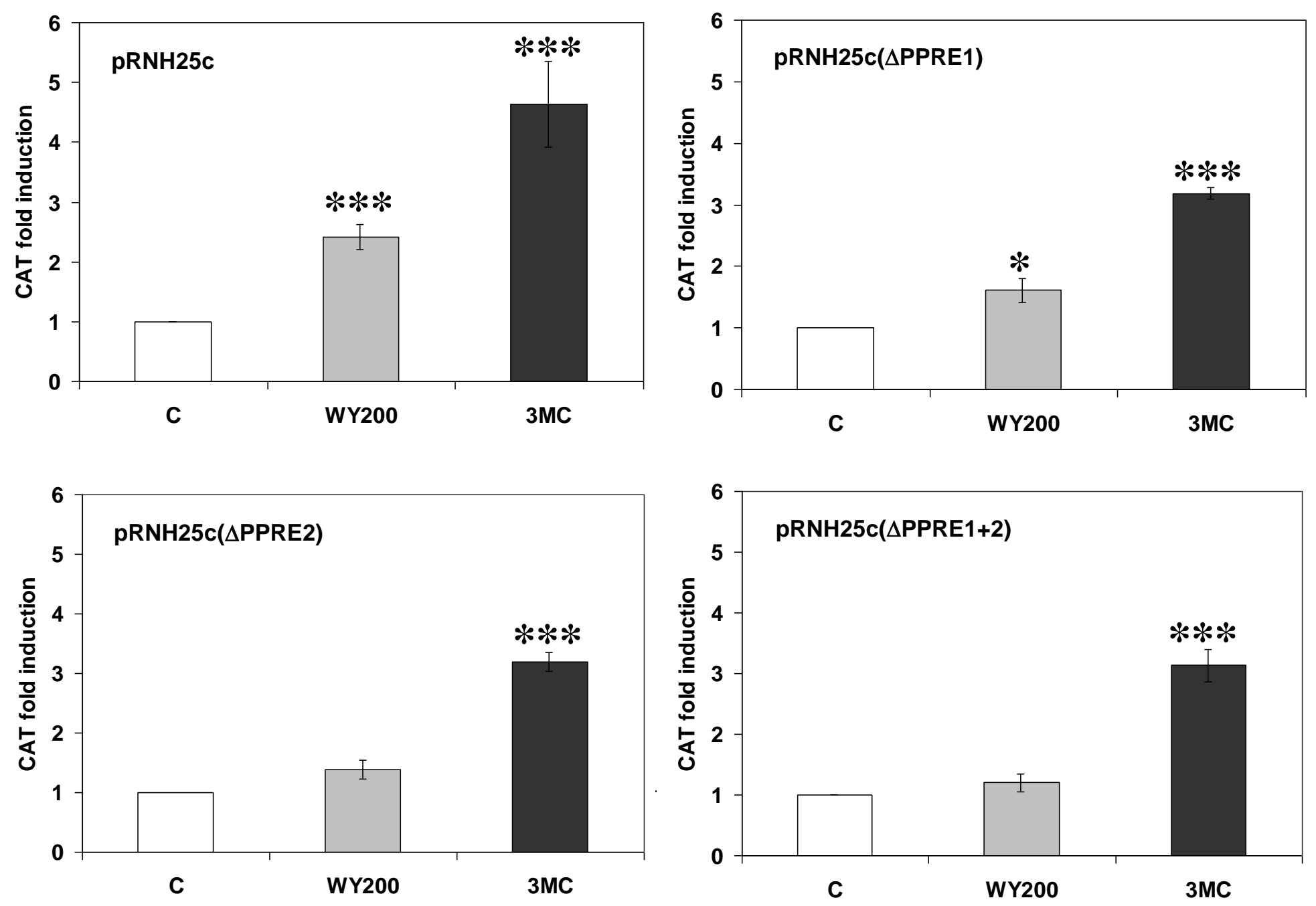

Figure 4 

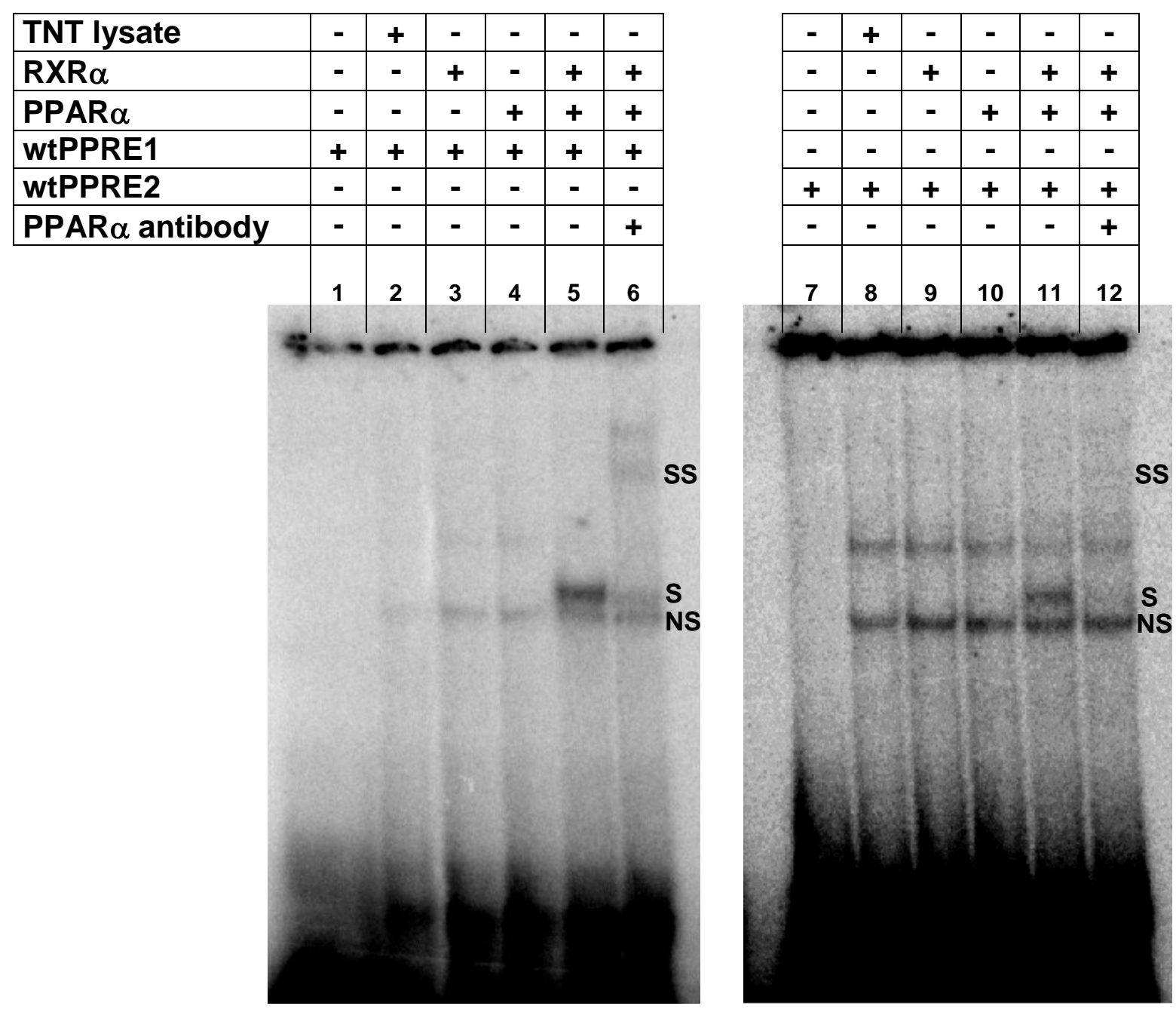

Figure 5 


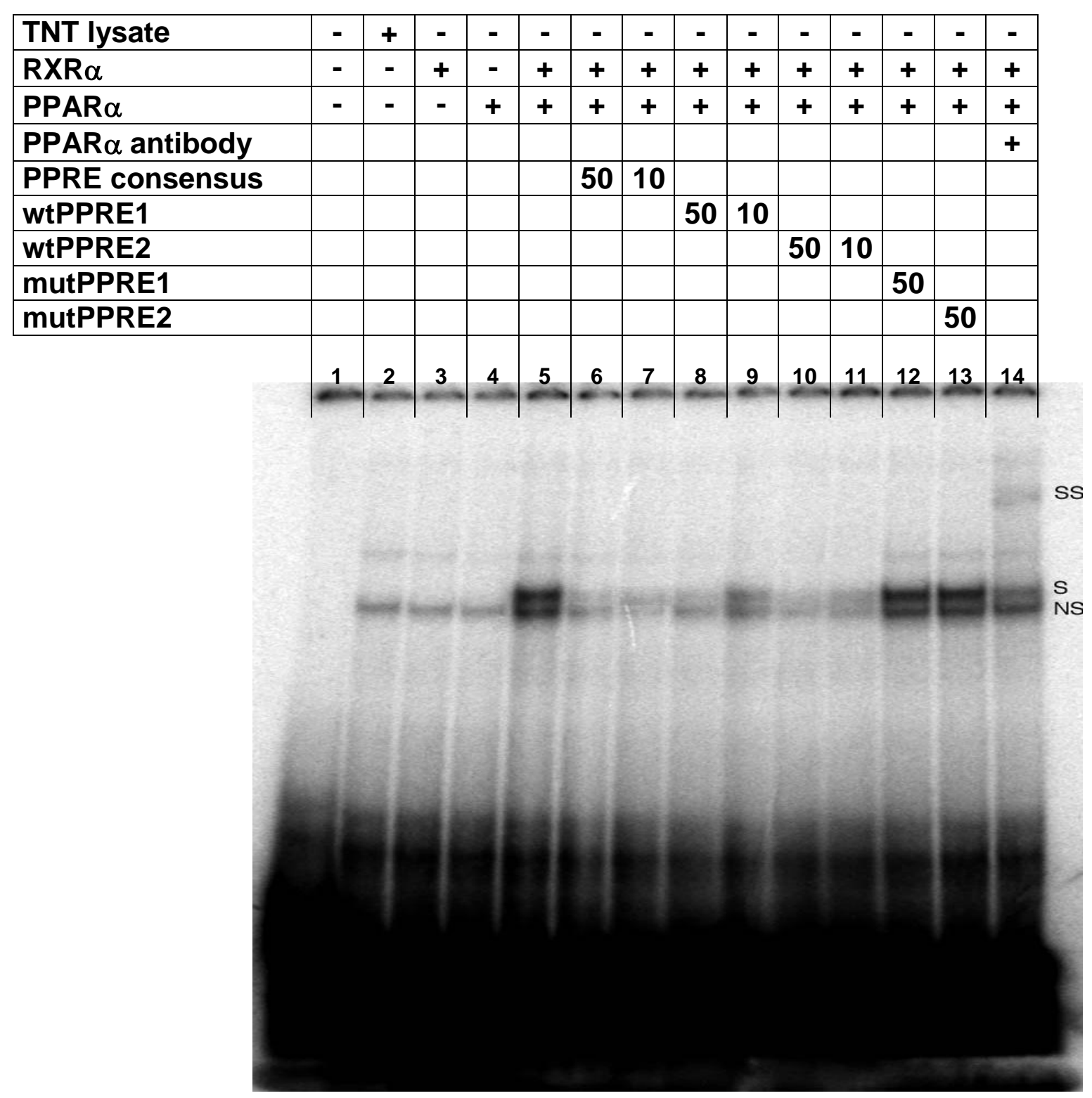

Figure 6 

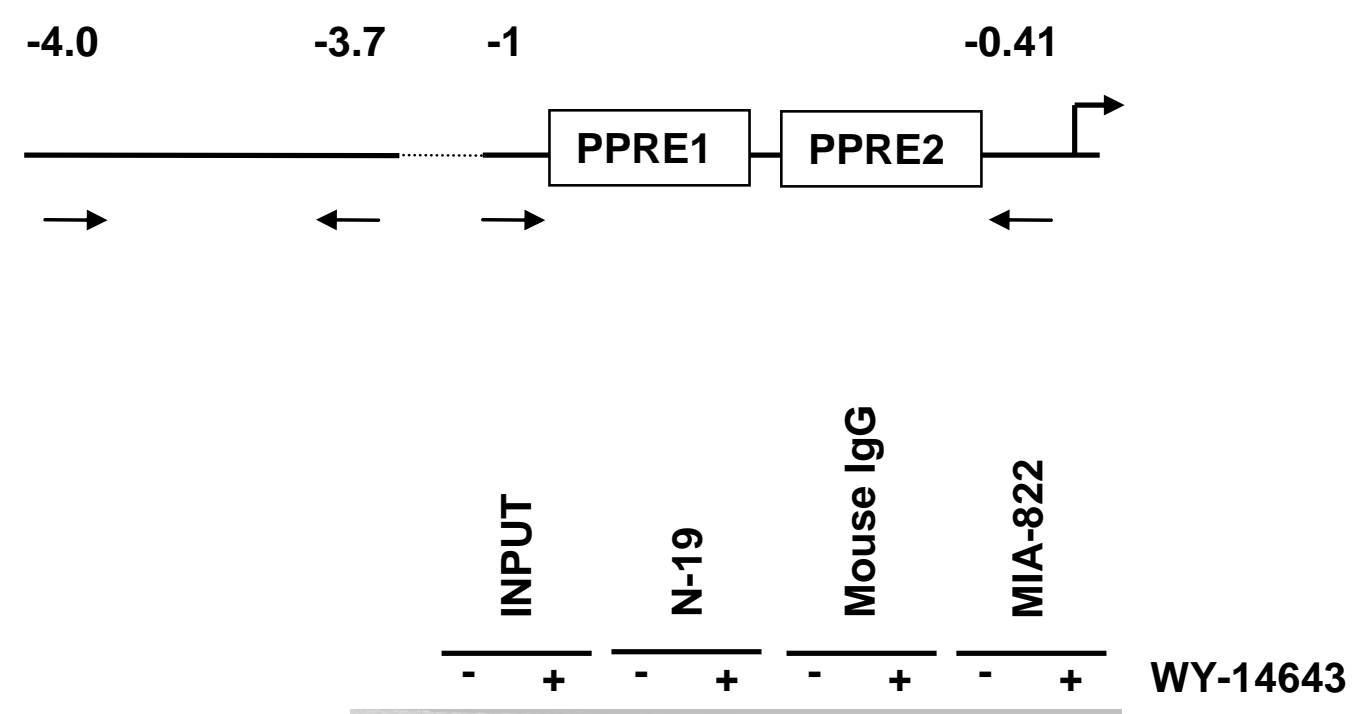

PCR - 4053 to -3780

PCR - 1000 to -413

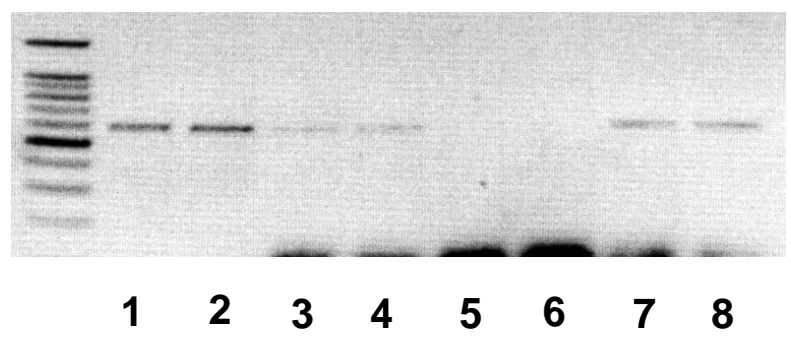

Figure 7 


\section{CYP1A1 PPRE1}

Human CYP1A1 (D10855) -940 a C g g g C C g C C I G A C C T c T G C C C C c t a g a g g g a T -908

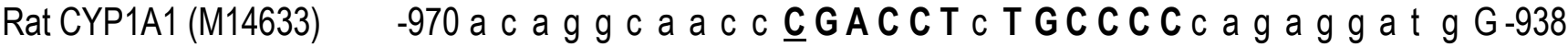

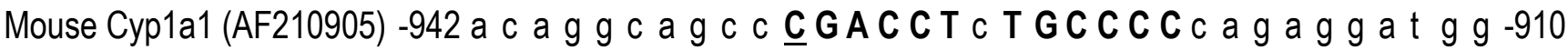
CYP1A1 PPRE2

Human CYP1A1 (D10855) -541 t c c g g c c c c g T G A C C T c A G G G C T g g g g t c g c a g -509 Rat CYP1A1 (M14633) $\quad-591 \mathrm{t}$ c c t g c c c t g T G A C C T c I G G G C T g g g g t c g c t g -559 Mouse Cyp1a1 (AF210905) -533 t c c t g t c c t g T G A C C T c I G G G C T g g g g t c g t t g -501

Figure 8 


\section{Figure Legends}

Figure 1. (A): CYP1A1 mRNA levels in CaCo-2 cells. CYP1A1 mRNA was evaluated by QRT-PCR after cell treatment during $6 \mathrm{~h}$ with either WY-14643 (10, 30, 100, 200, $400 \mu \mathrm{M}$ ), or $50 \mu \mathrm{M}$ BZF, or $50 \mu \mathrm{M}$ CF, or $100 \mu \mathrm{M}$ MEHP; or $200 \mu \mathrm{M}$ TZD; or $1 \mu \mathrm{M} 3$ MC. C: control. ${ }^{\star *}: p<0.01$ compared with control. ${ }^{* *}: p<0.001$ compared with control. (B): Effect of WY-14643 on CYP1A1 expression in different cell lines. CYP1A1 mRNA was evaluated by QRT-PCR after cell treatment during $6 \mathrm{~h}$ with $200 \mu \mathrm{M}$ WY14643 or $1 \mu \mathrm{M}$ 3-MC respectively in HepG2, keratinocytes, and A549.

Figure 2. Evaluation of EROD activity. EROD activity was evaluated after CaCo-2 cells treatment during $48 \mathrm{~h}$ with different WY-14643 concentrations $(10,30,100,200$ $\mu \mathrm{M})$ or $1 \mu \mathrm{M}$ 3-MC. C: control. ${ }^{* *}$ : $\mathrm{p}<0.01$ compared with control.

Figure 3. (A): Effect of WY-14643 on XRE activation. CaCo-2 cells were transfected with a construct where XRE drives CAT expression. After transfection, cells were treated $48 \mathrm{~h}$ with $200 \mu \mathrm{M}$ WY-14643 or $1 \mu \mathrm{M}$ 3-MC. CAT expression was evaluated using the CAT Elisa System. *: $p<0.05$ compared with control. (B): CaCo-2 cells were either untransfected or transfected with cDNA coding the PPAR $\alpha$ and untreated or treated with $200 \mu \mathrm{M}$ WY-14643 during $48 \mathrm{~h}$. CYP1A1 mRNA level was then evaluated by $Q-P C R$ as described in material and methods. ${ }^{* \star *}: p<0.001$ compared with cells which have been transfected with the empty vector and treated with WY-14643. 
Figure 4. Effect of PPRE mutations on CYP1A1 promoter activation. CaCo2 cells were transfected with the wild-type pRNH25c (A), or the pRNH25c( $P$ PPRE1) (B), or the pRNH25c( $\triangle \mathrm{PPRE} 2)(\mathrm{C})$, or the pRNH25c( $\triangle \mathrm{PPRE} 1+2)(\mathrm{D})$. Cells were then either untreated $(\mathrm{C})$ or treated with $200 \mu \mathrm{M}$ WY-14643 during $48 \mathrm{~h}$. CAT expression was evaluated by CAT ELISA System. ${ }^{*}$ : $p<0.05$ compared with control. ${ }^{* \star *}$ : $p<0.001$ compared with control.

Fig 5. EMSA using CYP1A1 specific PPRE $1 / 2$ sequences. RXR $\alpha$, PPAR $\alpha$ or both were produced by reticulocytes and incubated with CYP1A1 PPRE1 (lanes 1-6), or CYP1A1 PPRE2 (lanes 7-12). Lanes 1 and 7: free probe; lanes 2 and 8: TNT; lanes 3 and 9: RXR $\alpha$ alone; lanes 4 and 10: PPAR $\alpha$ alone; lanes 5 and 11: PPAR $\alpha / R X R \alpha$ heterodimer; lanes 6 and 12: PPAR $\alpha / R X R \alpha$ heterodimer + PPAR $\alpha$ antibody. S: shifted band; SS: super shifted band; NS: unspecific band.

Figure 6. Effect of unlabelled probes on EMSA. RXR $\alpha$, PPAR $\alpha$ lanes 3, 4 or both lanes 5-14 were produced by reticulocytes and incubated with PPRE consensus sequence. Competition with unlabeled 50-fold or 10-fold PPRE consensus lanes 6, 7 or CYP1A1 PPRE1 lanes 8,9 or CYP1A1 PPRE2 lanes 10,11 or 50 -fold of mutated CYP1A1 PPRE 1 lane 12 or CYP1A1 PPRE2 lane 13 were realized. Lane 1 corresponds to the free PPRE probe and lane 14 shows a super shift obtained with a specific PPAR $\alpha$ antibody. S: shifted band; SS: super shifted band; NS: unspecific band. 
Figure 7. Chromatin immunoprecipitation assays of the CYP1A1 promoter in $\mathrm{CaCo} 2$ cells. CaCo2 cells were treated with or without $200 \mu \mathrm{M}$ WY-14643 for $1 \mathrm{~h}$. Soluble chromatin was immunoprecipitated with mice IgG (lanes 5-6), or antibodies against human PPAR $\alpha$ (N19, lane 3-4; or MIA-822, lanes 7-8). Immunoprecipitates were analyzed by PCR with specific primers for the distal $(-4053$ to -3780$)$ or proximal (-1000 to -413$)$ CYP1A1 promoter as indicated. PCR was performed with total chromatin input (lanes 1-2).

Figure 8. Sequence alignment of CYP1A1 promoter from human, rat and mouse. Sequence alignment was performed using LFASTA analysis (http://www.infobiogen.fr/services/analyseq/cgi-bin/lfastan_in.pl). Gene accession numbers are noted in brackets. PPRE sites are noted in bold capital letters, and mismatches are underlined. 